\title{
Small Molecule
}

National Cancer Institute

\section{Source}

National Cancer Institute. Small Molecule. NCI Thesaurus. Code C48809.

A molecule with a low molecular weight that is not determined by a genome sequence. 